\title{
Mathematical Formulation Applied to Health, Disease, and Death Induced by SARS-COV2
}

\author{
Hafedh ABDELMELEK ${ }^{1 *}$, Amel HANINI ${ }^{1}$, Abdelhamid ADOUANI ${ }^{2}$, Amen Allah AMRI ${ }^{3}$, \\ Zihad BOUSLAMA ${ }^{4}$ \\ ${ }^{1}$ Laboratory of Integrated Physiology, Faculty of Sciences, University of Carthage, Jarzouna, Bizerte, \\ Tunisia. \\ ${ }^{2}$ Laboratory of Dynamic Systems and applications UR17ES21, University of Carthage, Jarzouna, Bizerte, \\ Tunisia. \\ ${ }^{3}$ BESTConseil Office. DR Center, 13 January 1952, 7000 Bizerte, Tunisia. \\ ${ }^{4}$ Laboratory of Aquatic and Terrestrial Ecology, Faculty of Sciences, University of Badji Mokhtar, BP 12, \\ 23000 Sidi Amar, Annaba, Algeria.
}

*Corresponding Author: Pr. Hafedh ABDELMELEK, University of Carthage, Faculty of Sciences of Bizerte, 7021 Jarzouna, Tunisia.

\begin{abstract}
Our previous theories point that health result from and equilibrium between Eukaryotes and Prokaryotes in Human or Animal. Interestingly, health could be interpretedby emointelligence equation based on Emotion (E) and Intelligence (I) of Eukaryotes and Prokaryotes in the case when Log (E Euk/E Prok) $=0$. In sum, good health could be related to the stability of the ratio $(R)$ of E Eukaryotes/ E Prokaryotes around one. By looking for possible interaction between Eukaryotes and Prokaryotes, we attempt to introduce a new concept of mathematical interpretation of disease such as COVID-19. Finally, when Log.(E Euk/E Prok) $=-\infty$ we have $E$ Euk=0, indicating a negative evolution of health leading to disease and death induced by SARS-COV-2
\end{abstract}

Keywords: Health, Death; Eukaryote, Prokaryote, SARS-COV-2.

\section{INTRODUCTION}

The present manuscript aims to propose a mathematical interpretation of Health, Disease, and Death in the different cases of COVID-19 by i) thinking as usual out of the box and ii) by introducing mathematical tools to better understand the evolution of Human or Animal from good Health, to Disease and Death. Our aim is to develop methodologies or theories able to understand Prokaryote-Eukaryote interactions and their implication in health stability and disease genesis in a special contextof COVID19. Nowadays, we can consider a concept of a "quantum information" 'governing the interactions of living system based on emointelligence equation between Eukaryotes (Human and Animal) and Prokaryotes (bacteria, parasites, virus like SARS-COV-2) (Abdelmelek et al, 2019). Health could result from natural quantum mechanisms based on One Nature One Emotion One Health concepts (Abdelmelek et al, 2018; 2019). Health could be understood as living systems coherence or harmony (Kaplan, 2001).
The good health in Human or Animals could be associated to the stability or equilibrium between Eukaryotes and Prokaryotes values giving a ratio $(\mathrm{R})$ near one. Interestingly, health could be interpreted by emointelligence equation based on Emotion (E) and Intelligence (I) of Eukaryotes and Prokaryotes when Log (E Euk/E Prok $=0$ and $E$ Euk/E Prok $=1$. Thus, every disruption of ratio E Euk/E Prokstability by microbes, xenobiotics, electromagnetic fields... etcgives both values ratio $<1$ or ratio $>1$. Interestingly, Emointelligence equation explain in part the disease genesis. The mathematical resolution of emointelligence equation could be based on three ratio values $(\mathrm{R}<1, \mathrm{R}=1, \mathrm{R}>1)$. Emotion could modulate the interaction of Prokaryote-Eukaryote during stress. In sum, when $\mathrm{R}<1$, the equation gives EEuk/EProk $<1$ so we have an increase of $E$ Prok related to infectious disease observed by SARS-COV-2 septicemia. By contrast, when $\mathrm{R}>1$, the equation gives $\mathrm{E}$ Euk/E Prok>1 so we have an increase of E Euk related to neoplasic process. Finally, 
when Log. (E Euk/E Prok) $=-\infty$ we have E Euk $=0$, indicating a death status induced by SARS-COV-2

Interestingly, we believe that emointelligence algorithm describe good health in Human or Animal with a harmony between E Euk and E Prok. In addition, disharmony between E Euk and E Prokinduced by SARS-COV-2 leads to COVID-19 and death.

More generally, a pool of emotion, algorithm and health might be fundamental for interaction of Euk (Human or Animal) and Prok (SARSCOV-2) rules to maintain good health. Interestingly, patients infected with SARSCOV-2 showed higher body temperature of $39.0^{\circ} \mathrm{C}$, leukocyte numbers and increased levels of plasma pro-inflammatory cytokines. Some of the severe cases that were admitted to the intensive care unit showed high levels of proinflammatory cytokines and TNF $\alpha$ that are reasoned to promote disease severity (Huang.et al, 2020). In addition, SARS-COV-2 induces hypoxia associated to an increase of erythropoiesis. Given that, leucocystosis and erythrocytosis during COVID-19 disease (Huang.et al, 2020) try to correct the total number of Euk cells compared to SARS-COV-2 and other microbesnumber in order to maintain the ratio $\mathrm{R}$ near 1 . If, the organism cannot maintain the ratio stability we will observe different complication (disease) and death.

Future interpretation to control the spread of the disease must be based to extensive measures to reduce interactions between SARS-COV-2 with person. The early death cases of COVID-19 outbreak occurred primarily in elderly people with low emotion, possibly due to a weak immune system that permits faster progression of viral infection and the ratio is low than 1 .

\section{THEORETICAL FOUNDATIONS}

Equation (1) $\mathrm{I}_{\text {Prok }}=\varepsilon \mathrm{E}_{\text {Prok }}^{\alpha} \mathrm{T}_{\text {Prok }} \quad$ (Eq1)

Equation (2) $\mathrm{I}_{\mathrm{Euk}}=\varepsilon \mathrm{E}_{\mathrm{Euk}}{ }^{\alpha} \mathrm{T}_{\mathrm{Euk}} \quad$ (Eq2)

$\left(\right.$ Eq2)/ (Eq1) $\quad \mathrm{I}_{\text {Euk }} / \mathrm{I}_{\text {Prok }}=\mathrm{T}_{\text {Euk }} / \mathrm{T}_{\text {Prok }} *\left(\mathrm{E}_{\text {Euk }} \mathrm{E}_{\text {Prok }}\right)^{\alpha}$

Constante 1 of $\mathrm{T}_{\text {Euk }} / \mathrm{T}_{\text {Prok }}=3.1510^{\wedge} 10$

$\log \mathrm{I}_{\text {Euk }} / \mathrm{I}_{\text {Prok }}=10+\alpha \log \left(\mathrm{E}_{\text {Euk }} \mathrm{E}_{\text {Prok }}\right)$

$f(x)=10+\alpha \log (x)$

I: Intelligence or Innovation, $\mathrm{T}$ : Time, $\mathrm{E}$ : Emotion, $\alpha$ : Factor and $\varepsilon$ : coefficient, Euk: Eukaryote, c: Prokaryote.

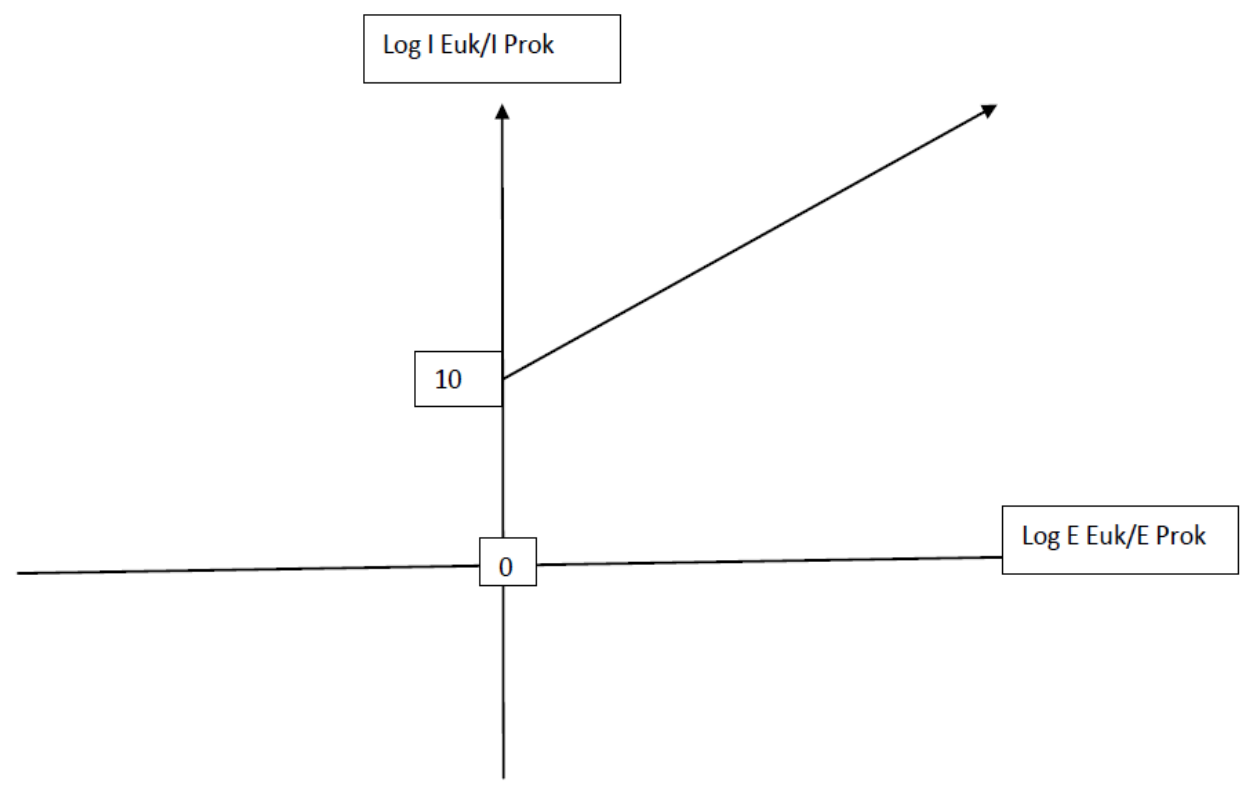

Figure1. Graphical representation of emointelligence equation applied to Prokaryote (Prok) and Eukaryote (Euk) in COVID-19

I: Intelligence or Innovation, E: Emotion.

Interestingly, the interpretation of emointelligence equation when Log (EEuk/EProk) $=0$ show positive values of Log (IEuk/IProk) near 10 and EEuk/EProk=1, indicating a management of algorithm in Euk and Prok leading to good health in Human or Animal. In addition, calculation of avalues $(-6,0,+6)$ indicate that IEuk/IProk explain health or disease status (Figure 1). By looking for possible interaction between lungs and intestine, we attempt to introduce an innovative concept called Prokaryote and Eukaryote stability or 
microbiota stability. Prokaryote-Eukaryote provides space-time model that correlates for algorithm stability in all emotional or intellectual processes. This present manuscript introduce a concept of Eco-Health suggesting the necessity of Human or Animal connectedness to nature and the necessity to preserve natural resources. Recent research demonstrate the existing of signals (QI) or information that circulate only between living systems in nature ((Berman et al, 2008; Bratmanet al, 2012; Abdelmelek et al, 2020) in order to explain the real significance of disease compared to health.

\section{CONCLUSION}

Our theories pointed to the existence of possible mechanism of ratio stability between Prokaryote and Eukaryote to maintain good health, indicating that Prokaryote-Eukaryote provides algorithm to understand health, disease, death status.

\section{REFERENCES}

[1] Hafedh ABDELMELEK, Amel HANINI, Abdelhamid ADOUANI, Amen Allah AMRI, Zihad BOUSLAMA. Emointelligence Algorithm Applied to SARS-COV2. ARC Journal of Neuroscience. 5(1):10-12(2020)
[2] Abdelmelek Hafedh, Abdelhamid Adouani, Amel Hanini1, Amen Allah Amri, Zihad Bouslama. Mathematical Formulation of Possible Entanglement between Human Consciousness and Unconsciousness Using Emointelligence Equation $\left(\mathrm{I}=\mathrm{T}^{*} \mathrm{E} \alpha^{*} \varepsilon\right)$ Clinical Research in Neurology Vol 2 Issue 2 (2019).

[3] Abdelmelek H, Amel Hanini, Ezzedine Nebil. Theories related to Emotional Bank System and Human Brain Double Door. J Neurosci Neurosurg (2018) Volume: 1.3 Manuscript ID: JNN-1-115

[4] Berman, M.G., Jonides, J., \& Kaplan, S. (2008). The cognitive benefits of interacting with nature. Psychological Science, 19(12), 1207-1212.

[5] Bratman, G. N., Hamilton, J. P., \& Daily, G. C. (2012). The [impacts of nature experience on human cognitive function and mental health. Annals of the New York Academy of Sciences, 1249, 118-136.

[6] Huang C., Y. Wang, X. Li, L. Ren, J. Zhao, Y. $\mathrm{Hu}$, et al. Clinical features of patients infected with 2019 novel coronavirus in Wuhan, China. Lancet, 395 (10223) (2020), pp. 497-506.

[7] Kaplan, R. (2001). The nature of the view from home: Psychological benefits. Environment and Behavior, 33(4), 507-542

Citation: Hafedh ABDELMELEK et al, " Mathematical Formulation Applied to Health, Disease, and Death Induced by SARS-COV2”, International Journal of Research Studies in Medical and Health Sciences. 2021; 6(4):24-26. DOI: https://doi.org/10.22259/ijrsmhs.0604005

Copyright: (c) 2021 Hafedh ABDELMELEK et al. This is an open-access article distributed under the terms of the Creative Commons Attribution License, which permits unrestricted use, distribution, and reproduction in any medium, provided the original author and source are credited. 